\title{
Effect of Inorganic Salts and Ureas on the Micellization Behavior of Antidepressant Drug Imipramine Hydrochloride at Various Concentrations and Temperatures
}

\author{
KABIR-UD-DIN ${ }^{*} \quad$ RUB Malik Abdul NAQVI Andleeb Z. \\ (Department of Chemistry, Aligarh Muslim University, Aligarh 202002, India)
}

\begin{abstract}
In the present study we report the micellization behavior of imipramine hydrochloride (IMP) in absence and presence of different concentrations of inorganic salts ( $\mathrm{LiCl}, \mathrm{NaF}, \mathrm{NaCl}, \mathrm{NaBr}$, and $\mathrm{KCl}$ ) and ureas (urea and thiourea) over the temperature range from 288.15 to $303.15 \mathrm{~K}$. The critical micellization concentrations $(\mathrm{cmc})$ of drug and drug + additive systems were determined by conductometric technique. With increasing temperature the $\mathrm{cmc}$ first increases then decreases. Maximum $\mathrm{cmc}$ values were obtained at $293.15 \mathrm{~K}$ with or without additives. In presence of inorganic salts the $\mathrm{cmc}$ value decreases which is explained on the basis of nature and ion size of the added ion. Urea and thiourea also decrease the $\mathrm{cmc}$ at low concentrations $\left(0.2 \mathrm{mmol} \cdot \mathrm{L}^{-1}\right.$ urea and $0.1 \mathrm{mmol} \cdot \mathrm{L}^{-1}$ thiourea), but, at higher concentrations, increase in $\mathrm{cmc}$ is observed. The related thermodynamic parameters are also evaluated and discussed.
\end{abstract}

Key Words: Antidepressant drug; Imipramine hydrochloride; Critical micelle concentration;

Conductivity; Inorganic salt

\section{Introduction}

Many pharmacologically active compounds are amphiphilic and self-associate in a surfactant-like manner. ${ }^{1,2}$ These include phenothiazines, analgesics, peptides, tranquillizers, antibiotics, tricyclic antidepressants, etc. Their self-association behavior depends on the structure of drug, $\mathrm{pH}$, temperature, nature and concentration of additives, etc. ${ }^{2-5}$ The concentration above which the amphiphiles form aggregates is known as critical micelle concentration $(\mathrm{cmc})$. Interactions of foreign ions (additives) with amphiphilic compounds are of interest in several areas of chemistry and biochemistry.

It is well known that salts (ionic compounds) and non-electrolytes (alcohols, diols, urea, thiourea) can alter the delicate balance of the hydrophobic-hydrophilic interaction of the micelle-forming surfactant in different ways. ${ }^{6-9}$ It is, therefore, important to understand the key role of forces that govern the micellization behavior in the presence of various additives. Salts decrease the cmc of ionic surfactants ${ }^{10}$ due to screening of the electrostatic repulsion among the polar head groups and movement of the hydrophobic alkyl chain away from aqueous environment, so that less electrical work is required to form micelles. Urea and its derivatives are well known protein denaturants ${ }^{11,12}$ because of their capacity to weaken hydrophobic interactions in aqueous solution. ${ }^{13}$ For this reason micellar solution properties have been affected by urea and its derivatives, which are determined by hydrophobic/hydrophilic interactions between surfactants and water. ${ }^{14,15}$ Indeed urea and thiourea have been shown to increase the $\mathrm{cmc}$ of ionic $\mathrm{c}^{16,17}$ and nonionic $\mathrm{c}^{18}$ surfactants and decrease the mean micellar hydrodynamic radius of the ionic micelles. ${ }^{19}$

Tricyclic antidepressant drugs, like imipramine hydrochloride (IMP), contain a ring core and alkylamine side chain (Fig.1) and their surfactant-like behavior is due to the alkylamine side chain which is manifested by self-association of these drugs. ${ }^{20}$ At low $\mathrm{pH}$ values, the tertiary nitrogen atom acquires a positive charge (protonated), while it becomes neutral (deprotonated) at high $\mathrm{pH}$ values. These compounds aggregate in water with 8 to 10 monomer units. ${ }^{20-22}$ The pharmacological activity of these drugs appears at low concentrations where ag-

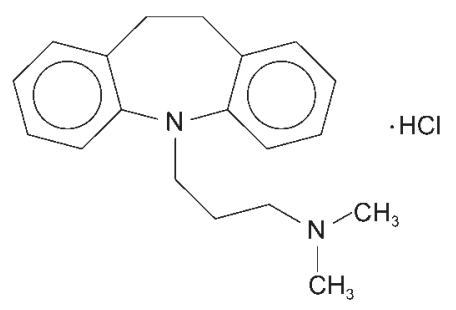

Fig.1 Molecular structure of imipramine hydrochloride (IMP)

Received: November 30, 2011; Revised: February 1, 2012; Published on Web: February 20, 2012.

"Corresponding author. Email: kabir7@rediffmail.com; Tel: +91-571-2703515.

The project was supported by the Council of Scientific and Industrial Research, New Delhi, India (01 (2208)/08/EMR-II).

(C) Editorial office of Acta Physico-Chimica Sinica 
gregation is negligible. ${ }^{5}$ However, the accumulation of drug can occur at certain site of organism after long period of administration, giving rise to formation of aggregates that are unable to pass through membranes; decreasing transport rate and consequently leading to adverse effect on health. Thus, the study of physicochemical properties of an amphiphilic drug is important from physical, chemical, biological, and pharmaceutical point of view for their implication.

In the present study, we report the effect of additives (inorganic salts ( $\mathrm{LiCl}, \mathrm{NaCl}, \mathrm{KCl}, \mathrm{NaF}, \mathrm{NaBr}$ ) and ureas (urea and thiourea)) on the micellar properties of an amphiphilic antidepressant drug, imipramine hydrochloride (IMP). Related thermodynamic parameters and degree of dissociation $(\alpha)$ are also evaluated. Electrolytes and urea are found in the body; hence knowledge of their effect on micellization will allow the better designing of effective therapeutic agents. In order to have better understanding of the mechanism on additives effect, study of the behavior of drug with change in co-ions and counterions is necessary. Keeping in view the above, we have performed conductometric technique for $\mathrm{cmc}$ measurement of pure IMP and IMP-additive systems.

\section{Experimental}

\subsection{Chemicals}

Imipramine hydrochloride (IMP, CAS Registry No. 113$52-0, \geq 98 \%$, Sigma, USA) was used as received. Inorganic salts, lithium chloride ( $\mathrm{LiCl}, 98 \%$, Loba chemie, India), sodium floride (NaF, 97\%, BDH, England), sodium chloride ( $\mathrm{NaCl}$, 99.9\%, BDH, England), sodium bromide ( $\mathrm{NaBr}, 99.8 \%$, Loba chemie, India), and potassium chloride $(\mathrm{KCl}, 99.9 \%, \mathrm{BDH}$, England) were used as received. Urea and thiourea were Sigma products with purity greater than $99.0 \%$, and were used as received.

\subsection{Conductivity measurements}

An ELICO conductivity meter (model CM 180, Hyderabad, India) was used to perform the experiments at different temperatures. The cell constant was $1.026 \mathrm{~cm}^{-1}$. The stock solution of drug IMP (with and without additive) was prepared in double-distilled water. A known volume of concentrated solution of drug was then added to water (in case without additive) or to a fixed concentration of additive solution with a pipette and thoroughly mixed, followed by measurement of conductance. Similar process was repeated after every addition. The specific conductance $(\kappa)$ was then plotted against concentration of the drug, Fig. 2 shows representative plots of specific conductivity $v s$ drug concentration of some selected systems at $298.15 \mathrm{~K}$. Break in plot is considered as the cmc of the solution. ${ }^{23}$ The error in cmc value was always less than $5 \%$.

\section{Results and discussion}

\subsection{Effect of additives on $\mathrm{cmc}$}

The critical micelle concentration (cmc) of IMP in pure water, determined by conductivity method, is found to be about

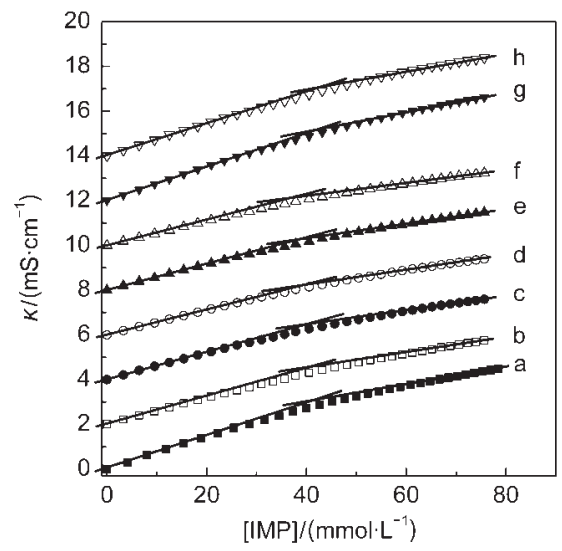

Fig.2 Representative plots of specific conductance $(\boldsymbol{c})$ vs [IMP] in absence and presence of $25 \mathrm{mmol} \cdot \mathrm{L}^{-1}$ additives (salts and ureas) at 293.15 K

Plots b, c, d, e, f, g, and h have been shifted successively by 2 scale units $\left(\mathrm{mS} \cdot \mathrm{cm}^{-1}\right)$ each. The additives used were: no additive $(\bullet), \mathrm{NaF}(\square), \mathrm{LiCl}(\bullet)$, $\mathrm{NaCl}(\circ), \mathrm{KCl}(\boldsymbol{\Delta}), \mathrm{NaBr}(\triangle)$, urea $(\boldsymbol{\nabla})$, thiourea $(\nabla)$.

$41.0 \mathrm{mmol} \cdot \mathrm{L}^{-1}$ at $293.15 \mathrm{~K}$, which is in accordance with the reported value. ${ }^{1,24}$ The cmc values of pure IMP and IMP-additive systems were determined at 288.15, 293.15, 298.15, and $303.15 \mathrm{~K}$ and the variations with different fixed concentrations of additives are shown in Fig.3.

Counterion binding to ionic micelles can be evaluated by electrochemical measurement. They are bound to micelles primarily not only by strong electrical field created by head groups, but also by specific interaction that depends upon head group and counterion type. ${ }^{25}$ Degree of counterion binding influences the cmc of amphiphiles. With the change in head group, a small effect on cmc has been observed; however, on changing a counterion, a pronounced effect has been observed. ${ }^{26}$ When the binding of counterion increased, the decrease in cmc and increase in aggregation number have been reported. ${ }^{27}$ As a counterion is changed from monovalent to divalent and trivalent the cmc is observed to decrease rapidly. ${ }^{26}$ This is primarily due to the decrease in electrostatic repulsion between ionic head groups. The size of counterion is also a determining factor for the $\mathrm{cmc}$ value. As the size of counterion increases, counterion binding also increases due to the decrease in hydrated radius of ion, and hence decrease in cmc occurs. ${ }^{28}$ Ionized counterions also disturb the structure of water around the ion where several water molecules are bound to counterion due to ion-dipole interactions. ${ }^{15}$

With increasing concentration of the added salt the cmc decreases (Fig.3). The decrease in $\mathrm{cmc}$ is due to the reduction in surface charge density of the micelle that leads to the lowering of Coulombic repulsion between the head groups.

Salts decrease the $\mathrm{cmc}$ in the order: $\mathrm{NaF}<\mathrm{LiCl}<\mathrm{NaCl}<\mathrm{KCl}<$ $\mathrm{NaBr}$. $\mathrm{F}^{-}, \mathrm{Cl}^{-}$, and $\mathrm{Br}^{-}$are the counterions for IMP cationic micelles whose binding follows the Hofmeister ${ }^{29}$ series, i.e., $\mathrm{F}^{-}<$ $\mathrm{Cl}^{-}<\mathrm{Br}^{-}$. As the size of counterion increases, the size of hydrated radius decreases. The size of counterion follows the order: $\mathrm{F}^{-}<\mathrm{Cl}^{-}<\mathrm{Br}^{-}$. It means that the hydrated size shows reverse 

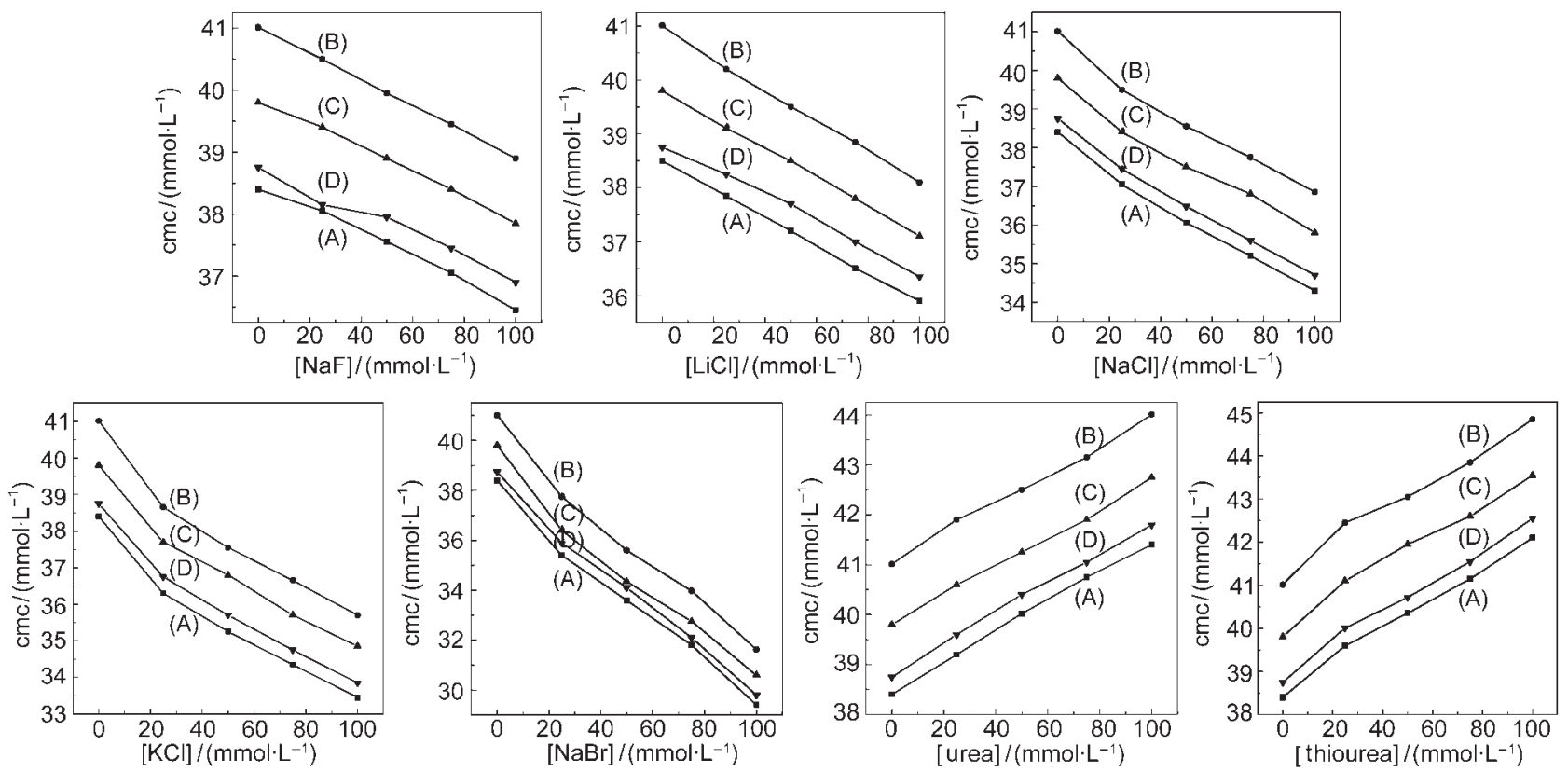

Fig.3 Critical micelle concentration (cmc) vs additive concentration in IMP-additive mixtures at different temperatures

$T / \mathrm{K}:$ (A) 288.15, (B) 293.15, (C) 298.15, (D) 303.15

trend, i.e., $\mathrm{Br}^{-}<\mathrm{Cl}^{-}<\mathrm{F}^{-30}$ Therefore, the tendency to increase the hydrophobicity of the system is maximum with $\mathrm{NaBr}$ addition, ${ }_{31,32}$ due to small hydrated radius, hence cmc decrease is maximum with $\mathrm{Br}^{-}$ion. The co-ions, for IMP micelles are $\mathrm{Li}^{+}, \mathrm{Na}^{+}$, and $\mathrm{K}^{+} . \mathrm{Li}^{+}$is least effective in decreasing the cmc due to small size and large hydrated radius and would act as a water-structure promoter decreasing the availability of water to the micelles. Counterions are more effective in decreasing the $\mathrm{cmc}$ as compared to co-ions. Therefore, upon addition of $\mathrm{LiCl}$ and $\mathrm{NaF}, \mathrm{LiCl}$ is more effective in reducing the cmc. At $303.15 \mathrm{~K}$, effect of $100 \mathrm{mmol} \cdot \mathrm{L}^{-1} \mathrm{NaCl}$ on $\mathrm{cmc}$ of IMP is quite close to the value obtained earlier. ${ }^{33}$

Nonelectrolytes (urea and thiourea) decrease the $\mathrm{cmc}$ at low concentration but at high concentration, increase it. The increase in cmc being more with thiourea. This may be due to difference in hydrogen bonding pattern within the crystal structure of urea (which forms chain) and thiouea (which forms ribbon).$^{34}$ In order to explain the effect of urea on the micellar properties of surfactants, two different mechanisms have been proposed, ${ }^{35,36}$ indirect and direct. In indirect mechanism urea only changes the water structure surrounding the solutes. The change in water structure is, according to the Frank and Evans theory, ${ }^{37}$ due to formation of the so-called 'iceberg structure' around the hydrocarbon chain of the surfactant molecule, hence, loss of entropy at their dissolution. The increase in $\mathrm{cmc}$ values in the presence of urea is due to its breaking ability of iceberg structure, without any large change in micellar state by droping the standard chemical potential.

In direct mechanism (favorable hydrogen bonding between urea and water) urea replaces some of the water molecules in the hydration shell of solutes. ${ }^{38}$ Indirect mechanism is widely accepted $^{39}$ and urea is put in the category of water-structure breaker. $^{40,41}$

In the present study, when urea is used in low concentration, it facilitates micellization, hence $\mathrm{cmc}$ decreases. The decrease in cmc occurs due to the combined effect of increase in hydrogen bonding and dielectric constant. As the hydrogen bonding of solvent (urea+water) increases, urea appears to enhance hydrophobic interactions and aggregation capacity, so that early micelle formation takes place. By increase in dielectric constant of solvent (water+urea) electrostatic repulsion decreases between IMP ions (cation). According to Coulomb's law, force between two charges is inversely proportional to the dielectric constant of the medium. Hence, by increase in dielectric constant, decrease in electrostatic repulsion and reduction in $\mathrm{cmc}$ is observed.

At higher concentration, urea behaves like a water-structure breaker, destroys the long range order characteristics of water and reduces the degree of water-water hydrogen bonding without replacing these interactions by strong urea-water hydrogen bonds. The effect of water structure breakers is similar to that caused by increase in temperature, ${ }^{42}$ hence increase in $\mathrm{cmc}$ has been observed at higher concentration of urea and thiourea. It is apparent that thiourea has a more pronounced water structure breaking property ${ }^{40,43}$ compared to urea, which is also an important factor for increasing the cmc more with addition of thiourea in comparison to latter.

\subsection{Effect of temperature on $\mathrm{cmc}$ and the degree of dissociation}

The micellization of surfactants (ionic or nonionic) is affected by temperature due to the change in interactions between hydrophobic tails and polar head groups. cme vs temperature studies have been performed to obtain information on these interactions. ${ }^{44}$ For ionic systems, cmc first decreases to a minimum 
value with temperature and then increases showing a U-shaped behavior. ${ }^{45,46}$ However, in some cases, continuous increase in cmc is observed with increasing temperature. ${ }^{47,48}$ For nonionic systems, cmc decreases continuously with an increase in temperature due to an increase in the hydrophobicity caused by destruction of hydrogen bonds between water molecules and hydrophilic group. ${ }^{49}$ However, in our case, as shown in Fig.3, an unusual behavior is shown by cmc with increase in temperature: the values first increase with temperature and then decrease. Similar behavior was observed in other amphiphilic drug systems too. ${ }^{50,51}$

The cmc value at a particular temperature is affected by two different ways: (i) dehydration of hydrophilic group, and (ii) disruption of structured water around the hydrophobic group. Dehydration of hydrophilic part favors micellization while disruption of structured water around the hydrophobic part disfavors the micellization. These two are the determining factors of cmc decrease or increase at a particular temperature.

In our system, cmc values of the drug and drug-additive systems increase at $293.15 \mathrm{~K}$, which means that disruption of structured water around the hydrophobic parts dominates over dehydration of hydrophilic part. However, at temperature 298.15 K and above, decrease in cmc is observed, which means that dehydration of hydrophilic part of drug is the dominating factor over the disruption of water molecules around the hydrophobic part. The particular structure of drug may also cause reduction of cmc at higher temperature, because, at higher temperature, a strong liberation of water (dehydration) around benzene ring also takes place.

The degree of dissociation $(\alpha)$ of IMP in pure form and IMP + additive systems was evaluated from the ratio of the slopes of the two straight lines above and below cmc from the plot of the conductivity against the drug concentration (Table 1). ${ }^{52}$ The degree of dissociation decreases with increase in electrolyte concentration ${ }^{53}$ and increase with the increase in temperature, which is also observed in case of ionic surfactants (where degree of binding decreases with increase in tempera- ture) ${ }^{54,55}$ In our case, similar trend of $\alpha$ has been obtained, i.e., with increase in temperature, $\alpha$ also increases, but not in all cases. The degree of binding is maximum with $\mathrm{Br}^{-}$ion $(\mathrm{NaBr})$ addition, because it has a large size and small hydrated radius. ${ }^{32}$ Degree of binding follows the same order as the effect of salts on the cmc, i.e., as for the salt which decreases the cmc maximum, degree of binding of that salt is also maximum. In case of urea and thiourea, degree of binding is more in case of urea because it increases the cmc less than thiourea.

\subsection{Thermodynamics}

Standard Gibbs energy $\left(-\Delta G_{\mathrm{m}}^{0}\right)$, enthalpy $\left(\Delta H_{\mathrm{m}}^{0}\right)$, and entropy $\left(\Delta S_{\mathrm{m}}^{0}\right)$ of micellization values were evaluated by using the following Eqs.(1)-(3):

$$
\begin{aligned}
& \Delta G_{\mathrm{m}}^{0}=(2-\alpha) R T \ln X_{\mathrm{cmc}} \\
& \Delta H_{\mathrm{m}}^{0}=-(2-\alpha) R T^{2}\left(\mathrm{~d} \ln X_{\mathrm{cmc}} / \mathrm{d} T\right) \\
& \Delta S_{\mathrm{m}}^{0}=\left(\Delta H_{\mathrm{m}}^{0}-\Delta G_{\mathrm{m}}^{0}\right) / T
\end{aligned}
$$

where $R, T$, and $X_{\mathrm{cmc}}$ are the universal gas constant, Kelvin temperature, and cmc in mole fraction unit, respectively.

The values of $\Delta G_{\mathrm{m}}^{0}$ obtained for pure IMP are similar to those obtained for other antidepressants. ${ }^{56,57}$ The $\Delta G_{\mathrm{m}}^{0}$ values are all negative and show slight variation with temperature as well as with increase in additive concentration and type, which implies that the drug-additive solutions are more stable (Table 1). For pure IMP, negative value of $\Delta G_{\mathrm{m}}^{0}$ increases with increasing temperature which indicates that micellization process is more spontaneous. Generally, similar behavior has also been observed by addition of additive (inorganic salts and ureas), which means by increasing temperature the negative value of $\Delta G_{\mathrm{m}}^{0}$ is increased but not significantly.

The $\Delta H_{\mathrm{m}}^{0}$ values of pure IMP are negative at $288.15 \mathrm{~K}$, i.e., process is exothermic at $288.15 \mathrm{~K}$, but by increasing temperature above $288.15 \mathrm{~K}$, the $\Delta H_{\mathrm{m}}^{0}$ values become positive, making the process endothermic. After increasing the temperature above $293.15 \mathrm{~K}$, the positive value of $\Delta H_{\mathrm{m}}^{0}$ increases. Similar trends are also observed for drug-additive mixtures (Table 1). At temperature $293.15 \mathrm{~K}$ and above, the endothermicity is due to dehydration of tricyclic nonpolar tails. The unusual behavior

\begin{tabular}{|c|c|c|c|c|c|c|c|c|c|c|c|}
\hline Additive & $\frac{\text { [Additive] }}{\left(\mathrm{mmol} \cdot \mathrm{L}^{-1}\right)}$ & $\frac{\mathrm{cmc}}{\left(\mathrm{mmol} \cdot \mathrm{L}^{-1}\right)}$ & $\alpha$ & $\frac{-\Delta G_{\mathrm{m}}^{0}}{\left(\mathrm{~kJ} \cdot \mathrm{mol}^{-1}\right)}$ & $\frac{\Delta H_{\mathrm{m}}^{0}}{\left(\mathrm{~kJ} \cdot \mathrm{mol}^{-1}\right)}$ & $\frac{\Delta S_{\mathrm{m}}^{0}}{\left(\mathrm{~J} \cdot \mathrm{K}^{-1} \cdot \mathrm{mol}^{-1}\right)}$ & $\frac{\mathrm{cmc}}{\left(\mathrm{mmol} \cdot \mathrm{L}^{-1}\right)}$ & $\alpha$ & $\frac{-\Delta G_{\mathrm{m}}^{0}}{\left(\mathrm{~kJ} \cdot \mathrm{mol}^{-1}\right)}$ & $\frac{\Delta H_{\mathrm{m}}^{0}}{\left(\mathrm{~kJ} \cdot \mathrm{mol}^{-1}\right)}$ & $\frac{\Delta S_{\mathrm{m}}^{0}}{\left(\mathrm{~J} \cdot \mathrm{K}^{-1} \cdot \mathrm{mol}^{-1}\right)}$ \\
\hline & & & & 288.15 & & & & & 293.1 & & \\
\hline \multirow[t]{12}{*}{$\mathrm{NaF}$} & 0 & 38.40 & 0.61 & 24.31 & -12.65 & 40.46 & 41.01 & 0.62 & 24.32 & 5.59 & 102.03 \\
\hline & 25 & 38.05 & 0.66 & 23.28 & -11.48 & 40.95 & 40.50 & 0.67 & 23.39 & 5.67 & 99.13 \\
\hline & 50 & 37.55 & 0.66 & 23.43 & -11.45 & 41.57 & 39.95 & 0.71 & 22.81 & 5.74 & 93.95 \\
\hline & 75 & 37.05 & 0.70 & 22.73 & -11.24 & 39.90 & 39.45 & 0.73 & 22.43 & 4.72 & 92.59 \\
\hline & 100 & 36.45 & 0.67 & 23.28 & -11.90 & 39.49 & 38.90 & 0.76 & 21.99 & 4.68 & 91.00 \\
\hline & \multicolumn{6}{|c|}{$298.15 \mathrm{~K}$} & \multicolumn{5}{|c|}{$303.15 \mathrm{~K}$} \\
\hline & 0 & 39.80 & 0.63 & 24.60 & 5.73 & 101.70 & 38.75 & 0.65 & 24.79 & 5.85 & 101.10 \\
\hline & 25 & 39.40 & 0.69 & 23.47 & 5.76 & 98.04 & 38.15 & 0.71 & 23.67 & 5.88 & 97.48 \\
\hline & 50 & 38.90 & 0.72 & 23.04 & 4.85 & 93.56 & 37.95 & 0.74 & 23.14 & 4.93 & 92.64 \\
\hline & 75 & 38.40 & 0.70 & 23.44 & 5.00 & 95.39 & 37.45 & 0.72 & 23.56 & 5.09 & 94.49 \\
\hline & 100 & 37.85 & 0.76 & 22.38 & 4.82 & 91.24 & 36.90 & 0.74 & 23.30 & 5.09 & 93.66 \\
\hline & \multicolumn{6}{|c|}{$288.15 \mathrm{~K}$} & \multicolumn{5}{|c|}{$293.15 \mathrm{~K}$} \\
\hline \multirow[t]{5}{*}{$\mathrm{LiCl}$} & 0 & 38.40 & 0.61 & 24.31 & -12.65 & 40.46 & 41.01 & 0.62 & 24.32 & 5.59 & 102.03 \\
\hline & 25 & 37.85 & 0.62 & 24.04 & -11.44 & 43.73 & 40.20 & 0.63 & 24.10 & 4.85 & 98.74 \\
\hline & 50 & 37.20 & 0.58 & 24.86 & -11.75 & 45.49 & 39.50 & 0.63 & 24.14 & 4.55 & 97.87 \\
\hline & 75 & 36.50 & 0.69 & 22.83 & -11.20 & 40.38 & 38.85 & 0.75 & 22.15 & 4.36 & 90.45 \\
\hline & 100 & 35.90 & 0.68 & 23.28 & -10.86 & 43.11 & 38.10 & 0.70 & 23.05 & 4.36 & 93.48 \\
\hline
\end{tabular}

Table 1 Physicochemical properties and related thermodynamic parameters for IMP-additive systems at various temperatures (evaluated on the basis of conductivity measurements) 
continued Table 1

\begin{tabular}{|c|c|c|c|c|c|c|c|c|c|c|c|}
\hline Additive & $\frac{\text { [Additive] }}{\left(\mathrm{mmol} \cdot \mathrm{L}^{-1}\right)}$ & $\frac{\mathrm{cmc}}{\left(\mathrm{mmol} \cdot \mathrm{L}^{-1}\right)}$ & $\alpha$ & $\frac{-\Delta G_{\mathrm{m}}^{0}}{\left(\mathrm{~kJ} \cdot \mathrm{mol}^{-1}\right)}$ & $\frac{\Delta H_{\mathrm{m}}^{0}}{\left(\mathrm{~kJ} \cdot \mathrm{mol}^{-1}\right)}$ & $\frac{\Delta S_{\mathrm{m}}^{0}}{\left(\mathrm{~J} \cdot \mathrm{K}^{-1} \cdot \mathrm{mol}^{-1}\right)}$ & $\frac{\mathrm{cmc}}{\left(\mathrm{mmol} \cdot \mathrm{L}^{-1}\right)}$ & $\alpha$ & $\frac{-\Delta G_{\mathrm{m}}^{0}}{\left(\mathrm{~kJ} \cdot \mathrm{mol}^{-1}\right)}$ & $\frac{\Delta H_{\mathrm{m}}^{0}}{\left(\mathrm{~kJ} \cdot \mathrm{mol}^{-1}\right)}$ & $\frac{\Delta S_{\mathrm{m}}^{0}}{\left(\mathrm{~J} \cdot \mathrm{K}^{-1} \cdot \mathrm{mol}^{-1}\right)}$ \\
\hline & & & & 298.15 & & & & & 303.1 & & \\
\hline & 0 & 39.80 & 0.63 & 24.60 & 5.73 & 101.70 & 38.75 & 0.65 & 24.79 & 5.85 & 101.10 \\
\hline & 25 & 39.10 & 0.66 & 24.16 & 4.93 & 97.56 & 38.25 & 0.69 & 23.92 & 4.95 & 95.24 \\
\hline & 50 & 38.50 & 0.68 & 23.79 & 4.54 & 95.50 & 37.70 & 0.69 & 24.01 & 4.65 & 94.55 \\
\hline & 75 & 37.80 & 0.69 & 23.69 & 4.73 & 95.31 & 37.00 & 0.73 & 23.45 & 4.74 & 93.02 \\
\hline & 100 & 37.10 & 0.73 & $\begin{array}{l}22.85 \\
288.15\end{array}$ & 4.38 & 91.34 & 36.35 & 0.74 & $\begin{array}{l}23.22 \\
293.1\end{array}$ & 4.51 & 91.47 \\
\hline \multirow[t]{10}{*}{$\mathrm{NaCl}$} & 0 & 38.40 & 0.61 & 24.31 & -12.65 & 40.46 & 41.01 & 0.62 & 24.32 & 5.59 & 102.03 \\
\hline & 25 & 37.05 & 0.58 & 24.90 & -12.56 & 42.84 & 39.50 & 0.62 & 24.31 & 5.24 & 100.79 \\
\hline & 50 & 36.06 & 0.70 & 22.77 & -11.93 & 37.63 & 38.55 & 0.61 & 24.63 & 5.48 & 102.72 \\
\hline & 75 & 35.20 & 0.63 & 24.08 & -13.18 & 37.84 & 37.75 & 0.68 & 23.38 & 5.51 & 98.53 \\
\hline & 100 & 34.30 & 0.70 & $\begin{array}{l}22.95 \\
298.15\end{array}$ & $\mathrm{~K}^{-12.83}$ & 35.13 & 36.85 & 0.62 & $\begin{array}{l}24.57 \\
303.1\end{array}$ & 5.91 & 103.97 \\
\hline & 0 & 39.80 & 0.63 & 24.60 & 5.73 & 101.70 & 38.75 & 0.65 & 24.79 & 5.85 & 101.10 \\
\hline & 25 & 38.40 & 0.64 & 24.46 & 5.34 & 99.94 & 37.45 & 0.69 & 24.08 & 5.32 & 97.03 \\
\hline & 50 & 37.50 & 0.70 & 23.49 & 5.29 & 96.54 & 36.48 & 0.67 & 24.60 & 5.62 & 99.68 \\
\hline & 75 & 36.80 & 0.70 & 23.62 & 5.64 & 98.13 & 35.60 & 0.73 & 23.51 & 5.68 & 96.28 \\
\hline & 100 & 35.80 & 0.73 & $\begin{array}{l}23.13 \\
288.15\end{array}$ & 5.64 & 96.57 & 34.70 & 0.73 & $\begin{array}{l}23.59 \\
293.1\end{array}$ & 5.83 & 97.04 \\
\hline \multirow[t]{10}{*}{$\mathrm{KCl}$} & 0 & 38.40 & 0.61 & 24.31 & -12.65 & 40.46 & 41.01 & 0.62 & 24.32 & 5.59 & 102.03 \\
\hline & 25 & 36.30 & 0.61 & 24.48 & -12.06 & 43.10 & 38.65 & 0.62 & 24.38 & 4.95 & 100.01 \\
\hline & 50 & 35.25 & 0.63 & 24.05 & -11.89 & 42.20 & 37.55 & 0.67 & 23.65 & 4.80 & 97.10 \\
\hline & 75 & 34.35 & 0.57 & 25.32 & -12.79 & 43.47 & 36.65 & 0.68 & 23.54 & 5.01 & 97.41 \\
\hline & 100 & 33.45 & 0.64 & $\begin{array}{l}24.14 \\
298.15\end{array}$ & $\mathrm{~K}^{-12.21}$ & 41.42 & 35.70 & 0.65 & $\begin{array}{l}24.11 \\
303.1\end{array}$ & 5.12 & 99.74 \\
\hline & 0 & 39.80 & 0.63 & 24.60 & 5.73 & 101.70 & 38.75 & 0.65 & 24.79 & 5.85 & 101.10 \\
\hline & 25 & 37.70 & 0.65 & 24.37 & 5.02 & 98.59 & 36.75 & 0.69 & 24.24 & 5.06 & 96.65 \\
\hline & 50 & 36.80 & 0.67 & 24.04 & 4.95 & 97.22 & 35.70 & 0.70 & 24.16 & 5.03 & 96.32 \\
\hline & 75 & 35.70 & 0.68 & 23.92 & 5.16 & 97.55 & 34.75 & 0.69 & 24.34 & 5.32 & 97.85 \\
\hline & 100 & 34.85 & 0.67 & $\begin{array}{l}24.37 \\
288.15\end{array}$ & 5.24 & 99.93 & 33.85 & 0.68 & $\begin{array}{r}24.67 \\
293.1\end{array}$ & 5.37 & 99.11 \\
\hline \multirow[t]{10}{*}{$\mathrm{NaBr}$} & 0 & 38.40 & 0.61 & 24.31 & -12.65 & 40.46 & 41.01 & 0.62 & 24.32 & 5.59 & 102.03 \\
\hline & 25 & 35.40 & 0.61 & 24.48 & -12.32 & 42.22 & 37.75 & 0.63 & 24.36 & 4.91 & 99.86 \\
\hline & 50 & 33.60 & 0.58 & 25.25 & -12.45 & 44.42 & 35.80 & 0.60 & 25.10 & 4.87 & 102.22 \\
\hline & 75 & 31.80 & 0.61 & 24.84 & -12.71 & 42.11 & 33.98 & 0.63 & 24.76 & 5.58 & 103.50 \\
\hline & 100 & 29.40 & 0.60 & $\begin{array}{l}25.28 \\
298.15\end{array}$ & $\mathrm{~K}^{-14.11}$ & 38.76 & 31.63 & 0.61 & $\begin{array}{l}25.34 \\
303.1\end{array}$ & 5.93 & 106.65 \\
\hline & 0 & 39.80 & 0.63 & 24.48 & 5.73 & 101.70 & 38.75 & 0.65 & 24.79 & 5.85 & 101.10 \\
\hline & 25 & 36.40 & 0.64 & 24.81 & 5.07 & 100.20 & 35.90 & 0.66 & 24.82 & 5.14 & 98.85 \\
\hline & 50 & 34.35 & 0.62 & 25.36 & 4.97 & 101.73 & 34.10 & 0.62 & 25.71 & 5.12 & 101.71 \\
\hline & 75 & 32.75 & 0.64 & 25.11 & 5.73 & 103.43 & 32.10 & 0.65 & 25.40 & 5.88 & 103.15 \\
\hline & 100 & 30.60 & 0.61 & $\begin{array}{l}25.93 \\
288.15\end{array}$ & 6.14 & 107.57 & 29.80 & 0.62 & $\begin{array}{l}26.30 \\
293.1\end{array}$ & 6.30 & 107.55 \\
\hline \multirow[t]{12}{*}{ urea } & 0 & 38.40 & 0.61 & 24.31 & -12.65 & 40.46 & 41.01 & 0.62 & 24.32 & 5.59 & 102.03 \\
\hline & 0.2 & 37.20 & 0.60 & 24.48 & -13.03 & 39.73 & 39.80 & 0.63 & 24.11 & 5.42 & 100.74 \\
\hline & 25 & 39.20 & 0.61 & 24.24 & -12.81 & 39.65 & 41.90 & 0.62 & 24.20 & 5.56 & 101.53 \\
\hline & 50 & 40.02 & 0.63 & 23.78 & -11.78 & 43.04 & 42.50 & 0.63 & 23.88 & 4.94 & 98.29 \\
\hline & 75 & 40.75 & 0.62 & 23.83 & -10.87 & 44.91 & 43.15 & 0.63 & 23.83 & 4.87 & 97.89 \\
\hline & 100 & 41.40 & 0.62 & $\begin{array}{l}23.74 \\
298.15\end{array}$ & $K^{-11.60}$ & 42.11 & 44.01 & 0.63 & $\begin{array}{l}23.84 \\
303.1\end{array}$ & 5.04 & 98.51 \\
\hline & 0 & 39.80 & 0.63 & 24.48 & 5.73 & 101.70 & 38.75 & 0.65 & 24.79 & 5.85 & 101.10 \\
\hline & 0.2 & 38.70 & 0.64 & 24.52 & 5.58 & 100.95 & 37.65 & 0.66 & 24.59 & 5.67 & 99.82 \\
\hline & 25 & 40.60 & 0.65 & 24.18 & 5.63 & 100.00 & 39.60 & 0.66 & 24.45 & 5.77 & 99.70 \\
\hline & 50 & 41.25 & 0.64 & 24.23 & 5.07 & 98.29 & 40.40 & 0.66 & 24.35 & 5.17 & 97.38 \\
\hline & 75 & 41.90 & 0.64 & 24.18 & 5.00 & 97.87 & 41.05 & 0.66 & 24.29 & 5.10 & 96.97 \\
\hline & 100 & 42.75 & 0.64 & $\begin{array}{l}24.09 \\
288.15\end{array}$ & 5.16 & 98.09 & 41.80 & 0.66 & $\begin{array}{l}24.20 \\
293.1\end{array}$ & 5.25 & 97.17 \\
\hline \multirow[t]{12}{*}{ thiourea } & 0 & 38.40 & 0.61 & 24.31 & -12.65 & 40.46 & 41.01 & 0.62 & 24.32 & 5.59 & 102.03 \\
\hline & 0.1 & 36.95 & 0.62 & 24.14 & -10.99 & 45.63 & 39.15 & 0.65 & 23.82 & 4.40 & 96.24 \\
\hline & 25 & 39.60 & 0.62 & 23.98 & -13.24 & 37.26 & 42.45 & 0.63 & 24.02 & 5.81 & 101.75 \\
\hline & 50 & 40.35 & 0.62 & 23.83 & -12.30 & 40.02 & 43.05 & 0.65 & 23.56 & 5.36 & 98.66 \\
\hline & 75 & 41.15 & 0.63 & 23.73 & -12.05 & 40.53 & 43.85 & 0.63 & 23.79 & 5.25 & 99.07 \\
\hline & 100 & 42.10 & 0.61 & $\begin{array}{l}23.88 \\
298.15\end{array}$ & $\mathrm{~K}^{-12.11}$ & 40.84 & 44.85 & 0.63 & $\begin{array}{l}23.73 \\
303.1\end{array}$ & 5.14 & 98.49 \\
\hline & 0 & 39.80 & 0.63 & 24.48 & 5.73 & 101.70 & 38.75 & 0.65 & 24.79 & 5.85 & 101.10 \\
\hline & 0.1 & 38.10 & 0.66 & 24.17 & 4.52 & 96.22 & 37.40 & 0.68 & 24.35 & 4.62 & 95.55 \\
\hline & 25 & 41.10 & 0.64 & 24.24 & 5.94 & 101.22 & 40.01 & 0.66 & 24.48 & 6.07 & 100.76 \\
\hline & 50 & 41.95 & 0.66 & 23.80 & 5.49 & 98.25 & 40.72 & 0.71 & 23.53 & 5.50 & 95.76 \\
\hline & 75 & 42.60 & 0.65 & 23.99 & 5.36 & 98.45 & 41.55 & 0.69 & 23.74 & 5.38 & 96.06 \\
\hline & 100 & 43.55 & 0.66 & 23.77 & 5.21 & 97.20 & 42.55 & 0.68 & 23.92 & 5.32 & 96.45 \\
\hline
\end{tabular}

and decrease in cmc at $293.15 \mathrm{~K}$ and above is a matter of discussion, but we are sure that this occurs due to the release of water molecules from the hydrophobic portion of drug, which is the cause of endothermicity as well as decrease in cmc.

The $\Delta S_{\mathrm{m}}^{0}$ value at low temperature $(288.15 \mathrm{~K})$ is small whereas at temperature $293.15 \mathrm{~K}$ and above the values increase sharply but the sign remains same for all systems indicating that micellization is an entropy driven process. The reason behind the sharp increase in entropy at $293.15 \mathrm{~K}$ and above is due to the particular structure of IMP. The IMP has two parts, one is aromatic hydrocarbon, the other one is saturated hydrocarbon. There is a very much difference in the heat of hydra- 
tion between these two parts of drug. Temperature below 293.15 K the liberation of water, only, around the saturated hydrocarbon takes place, so the entropy is low, but at temperature $293.15 \mathrm{~K}$ and above there is strong liberation of water around the aromatic hydrocarbon part of drug, so that entropy increases sharply. This reason is also the cause of the decrease in cmc above $293.15 \mathrm{~K}$. By increasing the temperature from 293.15 to $303.15 \mathrm{~K}, \Delta S_{\mathrm{m}}^{0}$ value for pure IMP decreases. This means that the entropic contribution decreases. The same behavior is also observed for IMP-additive mixtures but not in all cases (Table $1)$.

\section{Conclusions}

In this paper we study the micellization of an antidepressant drug, imipramine hydrochloride, in presence of salts and nonelectrolytes (urea/thiourea) at different temperatures. By using the obtained cmc values, the thermodynamic parameters are also evaluated and results are discussed on the basis of nature and size of additives. The $\mathrm{cmc}$ decrease follows the order: $\mathrm{NaF}<\mathrm{LiCl}<\mathrm{NaCl}<\mathrm{KCl}<\mathrm{NaBr}$. In the presence of urea/thiourea, $\mathrm{cmc}$ increases at higher concentration, the increase being more with thiourea, while cmc decreases at lower concentration. The $\Delta G_{\mathrm{m}}^{0}$ values come out to be negative for all systems. However, $\Delta H_{\mathrm{m}}^{0}$ values for pure drug as well as drug-additive systems are negative at $288.15 \mathrm{~K}$, and positive at higher temperatures. The $\Delta S_{\mathrm{m}}^{0}$ values are positive, their magnitude being more at 293.15 $\mathrm{K}$ and above.

\section{References}

(1) Attwood, D.; Florence, A. T. Surfactant Systems: Their Chemistry, Pharmacy and Biology; Chapman and Hall: New York, 1983.

(2) Schreier, S.; Malheiros, S. V. P.; de Paula, E. Biochim. Biophys. Acta 2000, 1508, 210.

(3) Attwood, D.; Natarajan, R. J. Pharm. Pharmacol. 1981, 33, 136.

(4) Atherton, A. D.; Barry, B. W. J. Colloid Interface Sci. 1985, 106, 479 .

(5) Attwood, D. Adv. Colloid Interface Sci. 1995, 55, 271.

(6) Calvaruso, G.; Cavasino, F. P.; Sbriziolo, C.; Liveri, M. L. J. Chem. Soc. Faraday Trans. 1993, 89, 1373.

(7) Ruiz, C. C.; Garcia-Sanchez, F. J. Colloid Interface Sci. 1994, 165,110 .

(8) Ruiz, C. C. Colloid Polym. Sci. 1995, 273, 1033.

(9) Gracie, K.; Turner, D.; Palepu, R. Can. J. Chem. 1996, 74, 1616.

(10) Zang, L.; Somasundaran, P.; Maltesh, C. Langmuir 1996, 12, 2371.

(11) Franks, F. Water, A Comprehensive Treatise, Vol. IV; Plenum Press: New York, 1978.

(12) Shellman, J. A.; Schellman, C. The Proteins, Vol. II; Neurath, H. Ed.; Academic Press: New York, 1974.

(13) Tanford, C. J. Am. Chem. Soc. 1964, 86, 2050.

(14) Tanford, C. The Hydrophobic Effect; Wiley: New York, 1980.
(15) Israelachvili, J. N. Intermolecular and Surface Forces; Academic Press: New York, 1992.

(16) Corkill, J. M.; Goodman, J. F.; Harrod, S. P.; Tate, J. R. Trans. Faraday Soc. 1967, 63, 240.

(17) Das Gupta, P. K.; Moulik, S. P. Colloid Polym. Sci. 1989, 267, 246.

(18) Schick, M. J. J. Phys. Chem. 1964, 68, 3585.

(19) Mazer, N. A.; Carey, M. C.; Kwasnick, R. F.; Benedek, G. B. Biochemistry 1979, 18, 3064.

(20) Taboada, P.; Attwood, D.; Ruso, J. M.; Suarez, M. J.; Sarmiento, F.; Mosquera, V. J. Chem. Eng. Data 1999, 44, 820.

(21) Sarmiento, F.; Lopez-Fontan, J. L.; Prieto, G.; Attwood, D.; Mosquera, V. Colloid Polym. Sci. 1997, 275, 1144.

(22) Taboada, P.; Attwood, D.; Ruso, J. M.; Garcia, M.; Mosquera, V. Phys. Chem. Chem. Phys. 2000, 2, 5175.

(23) Williams, R. J.; Phillips, J. N.; Mysels, K. J. Trans. Faraday Soc. 1955, 51, 728.

(24) Taboada, P.; Attwood, D.; Ruso, J. M.; Garcia, M.; Mosquera, V. Langmuir 2001, 17, 173.

(25) Fendler, J. H. Membrane Mimetic Chemistry; Wiley: New York, 1982.

(26) Myers, D. Surfactant Science and Technology; VCH Inc.: New York, 1988.

(27) Mukerjee, P. Adv. Colloid Interface Sci. 1967, 1, 242.

(28) Rosen, M. J. Surfactants and Interfacial Phenomena, 3rd ed.; Wiley: New York, 2004.

(29) Hofmeister, F. Arch. Exp. Pathol. Pharmacol. 1888, 24, 247.

(30) Nightangle, E. R., Jr. J. Phys. Chem. 1959, 63, 1381.

(31) Gonzalez-Perez, A.; Del Castillo, J. L.; Czapkiewicz, J.; Rodriguez, J. R. J. Phys. Chem. B 2001, 105, 1720.

(32) Rodriguez, J. R.; Gonzalez-Perez, A.; Del Castillo, J. L.; Czapkiewicz, J. J. Colloid Interface Sci. 2002, 250, 438.

(33) Alam, M. S.; Naqvi, A. Z.; Kabir-ud-Din. J. Chem. Eng. Data 2007, 52, 1326.

(34) Masunav, A.; Dannenberg, J. J. J. Phys. Chem. B 2000, 104, 806.

(35) Watlaufer, D. B.; Malik, S. K.; Stoller, L.; Coffin, R. L. J. Am. Chem. Soc. 1996, 86, 508.

(36) Enea, O.; Jolicoeur, C. J. J. Phys. Chem. 1982, 86, 3870.

(37) Frank, H. S.; Evans, M. W. J. Chem. Phys. 1945, 13, 507.

(38) Roseman, M.; Jencks, W. P. J. Am. Chem. Soc. 1975, 97, 631.

(39) Kresheck, G. C.; Scheraga, H. A. J. Phys. Chem. 1965, 69, 1704.

(40) Bonner, O. D.; Bednareck, J. M.; Arisman, R. K. J. Am. Chem. Soc. 1977, 99, 2898.

(41) Manabe, M.; Koda, M.; Shirahama, K. J. Colloid Interface Sci. 1980, 77, 189.

(42) Bhanumathi, R.; Vijayalakshamma, S. K. J. Phys. Chem. 1986, 90, 4666

(43) Burke, S. E.; Rodgers, M. P.; Palepu, R. Mol. Phys. 2001, 99, 517.

(44) Miller, D. D.; Magid, L. J.; Evans, D. F. J. Phys. Chem. 1990, 94,5921 . 
(45) Flockhart, B. D. J. Colloid Sci. 1961, 16, 484.

(46) Stead, J. A.; Taylor, H. J. Colloid Interface Sci. 1969, 30, 482.

(47) Kabir-ud-Din; Siddiqui, U. S.; Kumar, S.; Dar, A. A. Colloid Polym. Sci. 2006, 284, 807.

(48) Ruiz, C. C.; Diaz-Lopez, L.; Aguiar, J. J. Colloid Interface Sci. 2007, 305, 293.

(49) Becher, P. Nonionic Surfactants; Schick, M. J. Ed.; Marcel Dekker: New York, 1967.

(50) Lopez-Fontan, J. L.; Costa, J.; Ruso, J. M.; Prieto, G.; Sarmiento, F. J. Chem. Eng. Data 2004, 49, 1008.

(51) Kabir-ud-Din; Rub, M. A.; Naqvi, A. Z. J. Phys. Chem. B 2010,
114,6354 .

(52) Zana, R. J. Colloid Interface Sci. 1980, 78, 330.

(53) Asakawa, T.; Kitano, H.; Ohta, A.; Miyagishi, S. J. Colloid Interface Sci. 2001, 242, 284.

(54) Okano, T.; Tamura, T.; Nanoka, T.; Ueda, S.; Lee, S.; Sugihara, G. Langmuir 2000, 16, 3777.

(55) Gorski, N.; Kalus, J. Langmuir 2001, 17, 4211.

(56) Taboada, P.; Ruso, J. M.; Garcia, M.; Mosquera, V. Colloids Surf. A 2001, 179, 125.

(57) Taboada, P.; Martinez-Landeira, P.; Ruso, J. M.; Garcia, M.; Mosquera, V. Colloids Surf. A 2002, 197, 95. 